\title{
Modelo e indicadores de masculinidad igualitaria en la ficción televisiva gallega: caso de Fontealba y Serramoura de Televisión de Galicia
}

\section{Alexandre Pichel-Vázquez ${ }^{1}$ Lorena Gómez-Puertas ${ }^{2}$ Pilar Medina-Bravo ${ }^{3}$}

Recibido: 14/03/2018

Aprobado por pares: 19/06/2018
Enviado a pares: 09/04/2018

Aceptado: 21/09/2018

DOI: 10.5294/pacla.2019.22.3.9

Para citar este artículo / to reference this article / para citar este artigo Pichel-Vázquez, A., Gómez-Puertas, L. y Medina-Bravo, P. (2019). Modelo e indicadores de masculinidad igualitaria en la ficción televisiva gallega: caso de Fontealba y Serramoura de Televisión de Galicia. Palabra Clave, 22(3), e2239. DOI: http://doi.org/10.5294/ pacla.2019.22.3.9

\section{Resumen}

Desde los television studies, la ficción ambientada en la realidad coetánea del receptor constituye un espacio privilegiado para consolidar la normativa social, pero también para visibilizar nuevas tendencias. Con el objetivo general de contribuir al campo de los masculinity studies, este artículo analiza dos series dramáticas de éxito de la Televisión de Galicia (TVG) de 2017 como relatos de proximidad que podrían representar nuevas masculinidades alternativas al modelo tradicional. Para ello, se ha evaluado el tipo de masculinidad dominante en estas producciones televisivas a partir del análisis de la caracterización y las interacciones sociales de sus principales personajes masculinos. La metodología aplicada ha incluido una lectura

\footnotetext{
orcid.org/0000-0003-4653-0501. Universitat Pompeu Fabra, España.

2 orcid.org/0000-0003-2203-8352. Universitat Pompeu Fabra, España. lorena.gomez@upf.edu

3 orcid.org/0000-0002-9240-1084. Universitat Pompeu Fabra, España. pilar.medina@upf.edu
} 
en profundidad y el mapeo de relaciones paradigmáticas entre personajes, junto con el análisis de contenido multivariable que ha permitido observar correlaciones entre la edad y clase social de los personajes y los tipos de masculinidad. Los resultados sostienen una mayor afinidad a la masculinidad hegemónica conforme aumenta el poder ejercido por el personaje en el ámbito público o laboral. Se establece una correlación entre clase social y modelo de masculinidad, no así para la variable de edad. Y aunque se representan diferentes aproximaciones a modelos de masculinidad más igualitarios, los personajes que las sustentan se disocian de la esfera laboral como ámbito fundamental de construcción identitaria. Todo ello nos lleva a concluir que, a pesar de la creciente diversidad en la representación de las masculinidades en la ficción televisiva analizada, el modelo patriarcal definido desde el ámbito de lo público sigue siendo el hegemónico.

\section{Palabras clave (Fuente: tesauro de la Unesco)}

Género; masculinidad; ficción; televisión; programa de televisión; serie de televisión; clase social; programa de radiodifusión; Galicia; España; Fontealba; Serramoura. 


\section{Egalitarian Masculinity Model and Indicators in Galician TV Fiction: The Case of Televisión de Galicia's Fontealba and Serramoura}

\section{Abstract}

From television studies, fiction set in the receiver's contemporary reality is a privileged opportunity to consolidate social regulations, but also to make latest trends visible. In order contribute to the field of masculinity studies, this article analyzes two successful dramatic series of Television de Galicia (TVG) in 2017 as proximity stories that could represent new alternative masculinities to the traditional model. For this, the type of masculinity prevailing in these TV productions has been evaluated by analyzing the characterization and social interactions of their main male characters. The applied method has included in-depth reading and mapping of paradigmatic relationships among characters, together with multivariable content analysis that showed correlations between characters' age and social class and the type of masculinity. Results hold greater affinity with hegemonic masculinity as the power exercised by the character in the public or labor spheres increases. A correlation between social class and masculinity model is established, but not for the age variable. And although different approaches to more egalitarian masculinity models are depicted, the characters that embody them dissociate themselves from the labor sphere as a key element of identity construction. All this leads to conclude that, despite the growing diversity in the representation of masculinities in the TV shows concerned, the patriarchal model defined from the public sphere remains hegemonic.

\section{Keywords (Source: Unesco Thesaurus)}

Gender; masculinity; fiction; television; television programmes; television serials; social class; broadcasting programmes; Galicia; Spain; Fontealba; Serramoura. 


\section{Modelo e indicadores de masculinidade igualitária na ficção televisiva galega: caso de Fontealba e Serramoura de Televisión de Galicia}

\section{Resumo}

Desde os television studies, a ficção ambientada na realidade contemporânea do receptor constitui um espaço privilegiado para consolidar a normativa social, mas também para visibilizar novas tendências. Com o objetivo geral de contribuir para o campo dos masculinity studies, este artigo analisa duas séries dramáticas de sucesso da Televisión de Galicia (TVG) de 2017 como relatos de proximidade que poderiam representar novas masculinidades alternativas ao modelo tradicional. Para isso, foi avaliado o tipo de masculinidade dominante nessas produções televisivas a partir da análise da caracterização e das interações sociais de suas principais personagens masculinas. A metodologia aplicada inclui uma leitura em profundidade e o mapeamento de relações paradigmáticas entre personagens, junto com a análise de conteúdo multivariável que permitiu observar correlações entre a idade e a classe social das personagens e dos tipos de masculinidade. Os resultados demonstram uma maior afinidade à masculinidade hegemônica conforme aumenta o poder exercido pela personagem no âmbito público ou profissional. É estabelecida uma correlação entre a classe e o modelo de masculinidade, mas não para a variável de idade. Embora sejam apresentadas aproximações de modelos de masculinidade mais igualitários, as personagens que as sustentam estão dissociados da esfera profissional como contexto fundamental de construção identitária. Tudo isso nos leva a concluir que, apesar da crescente diversidade na representação das masculinidades na ficção televisiva analisada, o modelo patriarcal definido a partir do âmbito do público continua sendo o hegemônico.

\section{Palavras-chave (Fonte: tesauro da Unesco)}

Gênero; masculinidade; ficção televisão; programa de televisão; série de televisão; classe social; programa de radiodifusão; Galiza; Espanha; Fontealba; Serramoura. 


\section{Introducción}

El auge de la producción de ficción seriada para la televisión es un fenómeno que se extiende desde las creaciones norteamericanas con vocación universal a aquellas que copan la pantalla de los hogares como relatos de proximidad. En España, tanto en las cadenas televisivas generalistas de ámbito estatal como en las de ámbito autonómico, proliferan las series de ficción que buscan fidelizar a un público cada vez más difícil de retener.

La producción española de las últimas décadas ha consolidado la dramedia como género propio, junto con múltiples variantes de la comedia y del drama, preferentemente histórico, cuando no de ambiente profesional asociado al suspense (García de Castro, 2008). Ciertamente, son casi exclusivas de las televisiones autonómicas las ficciones dramáticas que recrean la actualidad en términos costumbristas, esto es, el espacio y tiempo de la vida cotidiana de sus espectadores. Así, los seriales de sobremesa de Euskal Telebista, Televisió de Catalunya, Canal Sur o Televisión de Galicia no han dejado de sucederse con éxito unos a otros en los últimos veinticinco años, explicando historias propias de sus conciudadanos. Estas ficciones constituyen espacios privilegiados para la dramatización de la sociedad (O’Donnell, 1999), así como refuerzos narrativos de los mecanismos de identidad de las "comunidades imaginadas" a las que se dirigen (Castelló, 2010, 2016a). Son el barómetro ideal de los problemas sociales de interés $\mathrm{y}$ un foro singular en el que observar las representaciones y los discursos dominantes en torno a cuestiones de género tan fundamentales como las que aquí nos ocupan.

En efecto, son diversos los trabajos que han sustentado la idea de crisis del modelo de masculinidad hegemónica o la diversificación de las masculinidades frente al referente patriarcal en la era contemporánea (Connell, 2005; Gill, 2014). La idea subyacente de conflictividad entre un modelo dominante y sus posibles alternativas convierte la representación de las masculinidades en un campo de investigación en especial interesante para las series dramáticas que la televisión ofrece como relatos de proximidad a sus espectadores. Desde esta perspectiva, se plantea el análisis de los modelos de masculinidad representados en las dos series dramáticas de éxito de la Televisión de Galicia (TVG) en 2017. 


\section{Marco teórico}

\section{La ficción como relato social}

La televisión puede reforzar creencias previas, validar o legitimar experiencias privadas del público, incrementar la prominencia de ideas y formas de pensar con las que se le familiariza o generar la agenda temática, priorizando los temas de los que preocuparse y configurando sus marcos interpretativos (Livingstone, 1990).

Si la televisión es aún hoy nuestro central storyteller y el paradigma narrativo nuestro modo de conocimiento dominante, resulta indiscutible el potencial socializador de la ficción televisiva (Lacalle \& Gómez, 2017). Pero más allá del papel conservador que tradicionalmente se le ha atribuido como instrumento para reafirmar o prescribir la normativa social a una comunidad, la ficción televisiva y, en especial, aquella dedicada a hablar "de nosotros y para nosotros", puede poner en duda la norma, problematizar la realidad o invitar a reconsiderarla desde la propuesta de alternativas, esto es, de realidades posibles, soñadas o temidas. Desde el marco de los estudios culturales, la ficción televisiva, entendida como revitalización de los mitos en su función fabuladora, constituye una "ampliación del horizonte de lo posible" que permite participar simbólicamente de una amplia gama de experiencias representadas (Buonanno, 2004, 2012). Es, en definitiva, una "realidad en subjuntivo" con la que los espectadores pueden comentar, comprender e interpretar su propia vida (Bruner, 2004).

Justamente por ello, para analizar la ficción televisiva dramática de corte realista ambientada en el contexto coetáneo de la audiencia, debe respetarse su condición de construcción textual — no equiparar su interpretación a la de la realidad de referencia- y, con ello, asimilar las distintas competencias que requiere a su espectador textual, genéricas y sociales (Dhoest \& Simon, 2016). Este es el punto de partida de los estudios de recepción de carácter etnográfico de la crítica cultural feminista o los television studies en el ámbito de los estudios culturales en el que se enmarca el presente trabajo, así como de los modelos explicativos del procesamiento afectivo y cognitivo de formatos narrativos desde la media psychology (Igar- 
tua, 2007; Braddock \& Dillard, 2016). Junto con estas aproximaciones, las líneas de usos y efectos o las de la comunicación prodesarrollo y los medios prosociales o el edutaintment, no hacen sino reafirmar la función educativa, preventiva y de orientación cognoscitivo social y cultural de las ficciones televisivas (Asbeek, Fransen \& Smit, 2016; Vasallo de Lopes, Simoes \& Da Rocha, 2002), sobre todo, de aquellas ficciones seriadas que presentan historias fragmentadas que se entrecruzan y diversidad de personajes y elementos de juicio. Ello permite que el espectador busque similitudes y diferencias entre personajes, interpretando y juzgando sus conductas desde una óptica moral e ideológica más amplia (Buckingham, 1987). De manera que las series de televisión acaban siendo guías de pensamiento y reflexión sobre uno mismo y sobre las relaciones sociales que tiene.

El punto de anclaje son los personajes y sus relaciones, pero lo que permite equiparar los marcos convencionales de las series de ficción con los que las personas usan en su vida cotidiana es la similitud de las situaciones de interacción. En este sentido, televisión y vida son simbólicamente iguales, esto es, estatutos de la realidad y, por ello, el análisis del personaje no puede desvincularse de las situaciones de interacción en las que aparece (Buonanno, 2004). Es de este modo que los espectadores construyen personajes coherentes como depósitos de atributos que pueden ser más o menos estereotipados o ambiguos, en función del número de personajes que intervienen en la serie, y la consecuente distribución y diversificación de rasgos que permite (Livingstone, 1990).

Por tanto, para el estudio de los modelos de masculinidad en la ficción televisiva seriada que aquí nos ocupa, en primer lugar, se analiza la estructura de relaciones paradigmáticas entre los personajes analizados $\mathrm{y}$, a continuación, se aplica un análisis narrativo de tipo fenomenológico que observa sus acciones como comportamientos reales a partir de las situaciones de interacción y más allá del rol narrativo que suscriben (Casetti \& Di Chio, 1999).

En la descripción de los personajes, se atienden específicamente las variables de género, edad y clase social. Cabe insistir aquí en que lo que se 
realiza es un análisis de la representación como contribución de las ficciones televisivas al imaginario social en torno a estas variables, esto es, de acuerdo con el rol de los medios en el proceso de naturalización o aceptación de ciertas categorías como una condición del mundo social (Couldry, 2008, 2011). Así, la variable de género o más aún la de clase social — ampliamente discutida en el ámbito de los estudios sociológicos — desde los television studies está sujeta a la observación de diversos indicadores que permiten situar a los personajes sin mediar una declaración previa (Bromley, 2000; Mantsios, 2003). En esta área de estudio, el conflicto narrativo suele surgir entre personajes diferenciados por una o más de estas variables (edad, género o clase social), ya que, tal y como sucede en el entretenimiento basado en la realidad (Oliva, 2013; Stiernsteldt \& Jakobsson, 2017), el drama se crea a partir de una base dicotómica que los enfrenta en el eje de poder. La relación entre estas variables cuenta con una amplia línea de investigación (Gaunlett, 2008) que se abre en la ficción con la obra pionera del British Film Institute sobre la soap británica Coronation Street ${ }^{4}$ (Dyer et al., 1981). Este tipo de serial, descrito como social realism, que sirve a su vez como referencia a algunas de las ficciones dramáticas de las televisiones autonómicas españolas, presenta estrategias de elaboración bidimensional en la representación de género y clase social. Así lo revela el trabajo de Jordan (1981), quien analiza cómo se resuelven aspectos incompatibles de género con la narrativa ficcional a través de la variable de clase social en la soap británica: frente a mujeres débiles y dependientes, como reclama el estereotipo social, se sitúan mujeres asertivas en roles narrativos centrales, estas últimas vinculadas a la clase obrera, en la que tradicionalmente han sido vistas como más fuertes que sus homólogas de clase media, con independencia del rango de edad que representan. Este es un ejemplo paradigmático de una línea de reflexión en torno a las representaciones de género con amplia trayectoria en la ficción televisiva española (Belmonte \& Guillamón, 2008; Menéndez, 2008), si bien aún reducida en el estudio específico de la masculinidad (Guarinos, 2013,2015). Viene complementada por estudios similares en los que se correlacionan variables de edad, género y

4 Coronation Street es una serie británica que se emitió por primera vez el 9 de diciembre de 1960 en la cadena Independent Television (ITV). La serie seguía las vidas de los residentes de la calle Coronation, formada mayoritariamente por personas de clase obrera. Ha resultado ser el segundo drama británico más premiado del Reino Unido, después de EastEnders. 
clase social, como los trabajos de Chicharro (2009, 2012) o Rueda (2009) sobre seriales de corte histórico o costumbrista, en la línea de análisis de la telenovela realista brasileña (Porto, 2005; Tufte, 2000), Galán (2007) sobre series de ambientación actual, o Lacalle y Gómez $(2016,2017)$ en los recientes usos y consumos multipantalla de la ficción.

\section{Modelos culturales de masculinidad}

Como ya advertía Butler (2004), el género es una estructura sociopolítica de poder que no está determinada ni es fija en el tiempo, sino que se relaciona con el contexto y se crea a través de su puesta en práctica. El género se entiende como el resultado de una construcción social cuyas manifestaciones dominantes están sujetas a cambio, y pueden sufrir modificaciones que las lleven de ser hegemónicas en un momento y grupo social dado a su desaparición (Connell \& Messerschmidt, 2005). La variable género nos habla, por tanto, de la importancia del poder y de las relaciones entre los grupos que lo ostentan para la creación de diferentes jerarquías dentro del sistema social. En palabras de Kimmel (2008, p. 48), "no tener que pensar en la raza blanca es uno de los lujos de ser blanco, tanto como no tener que pensar en el género es uno de los dividendos patriarcales de la desigualdad genérica [la traducción es nuestra]". Bourdieu (1998) estudió de qué manera la dominación del sistema patriarcal es una dominación masculina que se ejerce sobre las mujeres siguiendo dos formas predominantes: la coerción social o la violencia simbólica. Esta última consigue que se favorezca y se acepte la visión de la realidad que está impuesta por los hombres, silenciando a las mujeres. Sin embargo, el ejercicio de violencia simbólica también afecta a los hombres, creando vínculos de sumisión entre los que se acomodan más a la definición hegemónica masculina del momento y los que se alejan de ella. En su interés por analizar la dominación intramasculina, Connell (2005, pp. 76-81) describe cuatro modelos de masculinidad: a) la hegemónica, en la cual reside el poder y la caracterización dominante de lo masculino; b) la cómplice, que agrupa aquellos hombres que no entran por definición en la hegemónica pero que obtienen beneficios (que no quieren perder) en un sistema social que favorece el hecho de ser varón; c) la subordinada, que explica las relaciones de subordinación derivadas de la autoridad heterosexual; y d) la masculinidad marginal, que engloba el con- 
junto de masculinidades excluidas del sistema por el poder hegemónico. En un estudio posterior, se añade una nueva masculinidad, denominada masculinidad empresarial (Connell \& Wood, 2005), que tiene sus raíces en las prácticas de acción burguesas reactualizadas en el escenario neoliberal actual. Este modelo de masculinidad basa su identidad en la consecución de un mayor salario y, por ende, de un mayor poder. La caracterización de la masculinidad hegemónica descrita por Connell (2005) se corresponde con lo que Badinter (1993) ya describió como el "hombre duro", nada femenino, es o se siente poderoso, independiente y que recurre habitualmente al individualismo, llegando a utilizar la violencia en multitud de ocasiones. Este hombre duro está representado como falto de emociones, o eso da a entender, mas su característica es la dificultad de expresarlos y no tanto la ausencia de ellos. En el lado opuesto, el "hombre blando" es aquel que no ha tenido un liderazgo paterno fuertemente masculinizado y si mantiene algún tipo de relación amoroso-afectiva con una mujer independiente y fuerte que "ha desmantelado la masculinidad tradicional y puesto fin a su prestigio” (Badinter, 1993, p. 176).

Igualmente interesante es la reflexión de Gill (2014) sobre la adaptación del modelo de masculinidad hegemónica a los entornos neoliberales posfeministas (la masculinidad new lad). El concepto engloba a aquellos varones, normalmente jóvenes, que en público afirman reconocer la importancia de la causa feminista y del movimiento LGBTI, pero que, en contextos de mayor confianza, realizan comentarios ofensivos y degradantes (Linkon, 2014; Song \& Lee, 2012).

Debe señalarse, sin embargo, que en la actualidad están apareciendo nuevos modelos de masculinidad (Segarra y Carabí, 2000), que, sin llegar al ideal igualitario, están viviendo procesos de reformulación personal del modelo de masculinidad hegemónica que deben ser apoyados para poder ser finalizados (González \& Jurado, 2015; Guarinos, 2013, 2015).

Con todo lo anterior, el objetivo general del presente trabajo es analizar los modelos de masculinidad representados en dos series ambientadas en la Galicia actual para valorar si aparecen estos nuevos modelos y cómo interactúan con el modelo tradicional de masculinidad hegemónica. 


\section{Metodología}

Esta investigación tiene en cuenta dos aspectos significativos. En primer lugar, el análisis de la representación de las masculinidades en la ficción televisiva se focaliza en una de las televisiones autonómicas de mayor calado en su área de influencia, TVG, ${ }^{5}$ aún poco representada en los estudios académicos de comunicación, más allá de los aspectos legales o de política cultural (Castelló, 2004, 2016b). A diferencia de las otras comunidades autónomas consideradas históricas por la Constitución Española de 1978, con cultura y lengua propias reconocidas, Galicia no ha protagonizado episodios significativos de conflictividad identitaria en la etapa democrática. Su televisión autonómica comparte, sin embargo, las finalidades propias de sus homólogas vascas, catalanas o andaluzas, como televisiones de proximidad que plantean la producción propia de relatos ficcionales ambientados en los valores idiosincrásicos de sus comunidades culturales. En segundo lugar, tal y como se ha avanzado, el estudio de las masculinidades en la ficción gallega se analiza desde la propuesta de la interseccionalidad (Crenshaw, 1991), más concretamente la variable género en intersección con la variable de la clase social del personaje masculino.

De acuerdo con lo anterior, el objetivo general es el análisis de los modelos de masculinidad que aparecen en la ficción televisiva seriada gallega de mayor audiencia. Como objetivos específicos se plantea el estudio de los siguientes aspectos: a) tipo de caracterización de los personajes masculinos principales de las series de ficción gallega que conforman la muestra; y b) relación entre el modelo de masculinidad con la clase social del personaje.

\section{Muestra de estudio y criterios de selección}

Se han seleccionado dos series en emisión de TVG: Fontealba, serie dramática producida por Atlántida Media para la sobremesa diaria (15:45h) desde septiembre de 2016, y Serramoura, un drama policiaco seriado producido por Voz Audiovisual y que inició su emisión en octubre de 2014 los domingos en prime time. A diferencia de otras producciones de éxito de

5 Según últimos datos, el grupo de radiotelevisión autonómico gallego, CRTVG, se sitúa como una de las cadenas autonómicas de mayor peso en su territorio, con un 10,8 \% de shareo cuota de pantalla, esto es, de porcentaje de espectadores respecto del total que consume televisión (Barlovento Comunicación, 2017). 
TVG como O final do camino (drama histórico ambientado entre 1075 y 1220), Augasquentes (comedia familiar) o Escoba! (comedia irónica protagonizada por mujeres), ambas series pertenecen al género dramático y están ambientadas en la Galicia actual, lo que resulta esencial para interpretar la ficción como relato de un mundo posible en diálogo con la realidad experimentada por la audiencia, y establecer una relación parasocial con personajes de tratamiento realista.

Fontealba es una serie dramática de emisión diaria que acabó en julio de 2017 tras 200 capítulos y manteniéndose en un share medio del 12,5\%, lo que la situaba a apenas 1000 espectadores de diferencia de la producción de la televisión pública estatal, Acacias 38, y 4000 espectadores por encima de la homóloga de Antena 3, Amar es para siempre (ambas telenovelas de corte histórico). ${ }^{6}$ Narra las vivencias de la familia Douro y de los demás habitantes de la villa. Los Douro, personajes centrales de la trama, son los propietarios de un manantial y de un invernadero de cultivo de flores y plantas. Los episodios analizados en la serie son los comprendidos entre el 126 y el 145, con una duración media de 48 min y 41 s. Los personajes masculinos son ocho y todos participan en más de la mitad de los episodios: Luis Douro, Xaquín, Gonzalo Vilar, Andrés Douro, Roberto, Fonso Douro, Toño y Ton.

Serramoura está en su quinta temporada, es de emisión semanal y se ha emitido un total de 104 capítulos. $^{7}$ Su cuota de pantalla se sitúa entre el 13 y el $16 \%$, con una audiencia acumulada de más de 214000 espectadores, de modo que es líder absoluto en su franja de emisión frente a la com-

6 Amar es para siempre es una telenovela ambientada en la guerra civil y los primeros años del franquismo, producida por la productora Diagonal TV inicialmente para la televisión pública española (TVE1). Empezó a emitirse con el título Amar en tiempos revueltos en 2005 en la franja horaria de tarde, hasta romper el acuerdo siete años después y reestrenarse como Amar es para siempre en 2013 en la televisión privada estatal Antena 3 TV. Cuenta con una veintena de premios y otros tantos reconocimientos como finalista, se ha emitido en casi 30 países y a través de TVE Internacional, Telemundo y NBC Universo. En España, acumula más de 2,5 millones de espectadores fieles. Acacias 38, producida por Boomerang TV en colaboración con TVE1, se emite en la televisión estatal pública desde 2015 en la misma franja, superando el millón de espectadores. Se ambienta en 1899, en un barrio burgués donde se articulan múltiples relaciones entre ricos y pobres (referentes como Dowton Abbey o Criadas y señoras). También se emite por TVE Internacional y Canale 5.

7 A 08/02/2018.

12 Modelo e indicadores de masculinidad igualitaria en la ficción televisiva... - Alexandre Pichel-Vázquez y otros 
petencia de las cadenas de cobertura estatal. Serramoura es una pequeña villa imaginaria de Galicia donde la industria maderera es la principal fuente de ingresos del pueblo. La trama se basa en las vivencias de la pareja de policías Marga Neira y Diego Bazán tras la llegada de este último al cuartel de la Guardia Civil del pueblo. Además, hay un conflicto entre las dos grandes familias poseedoras de la industria maderera de la zona, los Soutelo y los Fiúza. Para el estudio, se ha seleccionado desde el episodio 60 (temporada cuarta) al episodio 79 (temporada quinta). La duración media de los episodios es de 69 min y $7 \mathrm{~s}$. El análisis se centrará en ocho personajes masculinos: Diego Bazán, Tomás Penedo, Quique Parcero, Pancho Suárez, Evaristo Fiúza, Hugo Aradas, Moncho Neira y Santos Fiúza. Para el análisis, se han seleccionado todos aquellos personajes masculinos que se han mantenido fijos y constantes en los que eran los 20 últimos episodios en el momento de llevar a cabo el estudio y bajo el criterio de que aquellos que no llegasen al $50 \%$ de los episodios $(\mathrm{n} \geq 10)$ serían descartados. Así, el total de la muestra de análisis ha acabado siendo de 40 episodios (20 episodios por serie) y 16 personajes masculinos ( 8 por serie).

\section{Técnicas de análisis}

El punto de partida para el análisis de ambas series de ficción es una lectura en profundidad (close reading; Buonanno, 1999; O’Donnell, 1999) que permite visualizar el mapa de relaciones paradigmáticas entre los diferentes personajes que las pueblan, tanto en el planteamiento inicial (a partir de las sinopsis argumentales y los tres primeros episodios) como en la secuencia de capítulos analizados. Esta información nos ha de permitir interpretar los datos que obtendremos a continuación del análisis de contenido cuantitativo de los personajes en las diferentes situaciones de interacción en las que aparecen.

Para la consecución de los objetivos del estudio, se plantea el diseño ad hoc de una plantilla de análisis para los personajes que recoge la caracterización y el grado de masculinidad en los personajes masculinos siguiendo tres apartados:

- Datos identificativos y sociodescriptivos del personaje (nombre, edad, puesto de trabajo, jerarquía de poder). 
- Codificación de la variable ordinal de clase social en cinco niveles (clase baja, clase media-baja, clase media, clase media-alta y clase alta) de acuerdo con los referentes previos en el campo de los television studies (Chicharro, 2009, 2012; Jakobsson \& Stiernstedt, 2018, Tufte, 2000).

- Evaluación de los indicadores de masculinidad igualitaria mostrados en cada situación de interacción visionada a través de 26 indicadores (tabla 1), según la propuesta de Guarinos (2013), el análisis de paternidad corresponsable de González y Jurado (2015) y la inclusión del modelo de masculinidad new lad de Gill (2014).

\section{Tabla 1. Indicadores de masculinidad igualitaria}

\begin{tabular}{|l|l|}
\hline Es capaz de expresar sus sentimientos & Colabora con compañeras de trabajo \\
\hline Cuida su aspecto físico & No ejerce violencia en el ámbito familiar \\
\hline No expresa comentarios homófobos & No ejerce violencia en el ámbito profesional \\
\hline No posee comportamiento homófobo & Acepta a las mujeres como superiores profesionales \\
\hline Colabora en tareas de limpieza en casa & Alienta a una mujer en el ascenso profesional \\
\hline Hace la compra & Tiene amistades femeninas \\
\hline Cocina & Permite la toma de decisiones a la mujer \\
\hline Comparte tiempo de ocio con los hijos (si los tiene) & No cambio de actitud ante hombres o mujeres \\
\hline Cuida a los hijos (si los tiene) & No se siente superior a la mujer \\
\hline Ejerce labores domésticas igual o más que su pareja & No le preocupan temas tradicionalmente masculinos \\
\hline Ejerce el cuidado de sus hijos igual o más que su pareja (si los tiene) & No consume alcohol \\
\hline Antepone su familia a su trabajo & No tiene aficiones de ocio masculinas \\
\hline Antepone su familia a sus aficiones & No toma la iniciativa en las relaciones sexuales \\
\hline
\end{tabular}

Fuente: elaboración propia a partir de Guarinos (2013), González y Jurado (2015) y Gill (2014).

El análisis unidireccional ANOVA entre las variables de clase social y tipo de masculinidad se ha realizado mediante SPSS, versión 19 para el tratamiento estadístico y el establecimiento de las correlaciones entre categorías. Las figuras que ilustran la relación que existe entre dos variables de escala se han construido mediante el paquete ofimático de Excel. El coeficiente kappa $(\kappa)$ de Cohen, aplicado entre los tres investigadores sobre el $10 \%$ de la muestra, indica buena fiabilidad interobservadores (entre $\kappa=0,746$ y $\kappa=0,638, p=0,00)$. De las 640 plantillas de codificación generadas (16 personajes, 40 episodios), se han obtenido 16640 resultados bidimensionales. 


\section{Resultados}

En primer lugar, presentamos los datos identificativos del personaje, su clase social e indicadores de masculinidad igualitaria. En segundo lugar, examinamos las correlaciones entre las categorías de masculinidad para corroborar el grado de consistencia de la representación de los personajes masculinos y posibles tendencias características de masculinidad en las series de ficción analizadas.

\section{Caracterización de personajes e indicadores de masculinidad igualitaria}

Los personajes masculinos de Fontealba y Serramoura se mueven en un abanico amplio de modelos de masculinidad (figura 1). Un diferencial que llega casi a los 35 puntos en Fontealba (0,3308 en el nivel más bajo que presenta el personaje de Ton y 0,6792 en el más alto que presenta el personaje Gonzalo Vilar) y es superada en más de seis puntos en Serramoura.

\section{Figura 1. Caracterización e indicadores de masculinidad igualitaria en los personajes masculinos de Fontealba y Serramoura.}

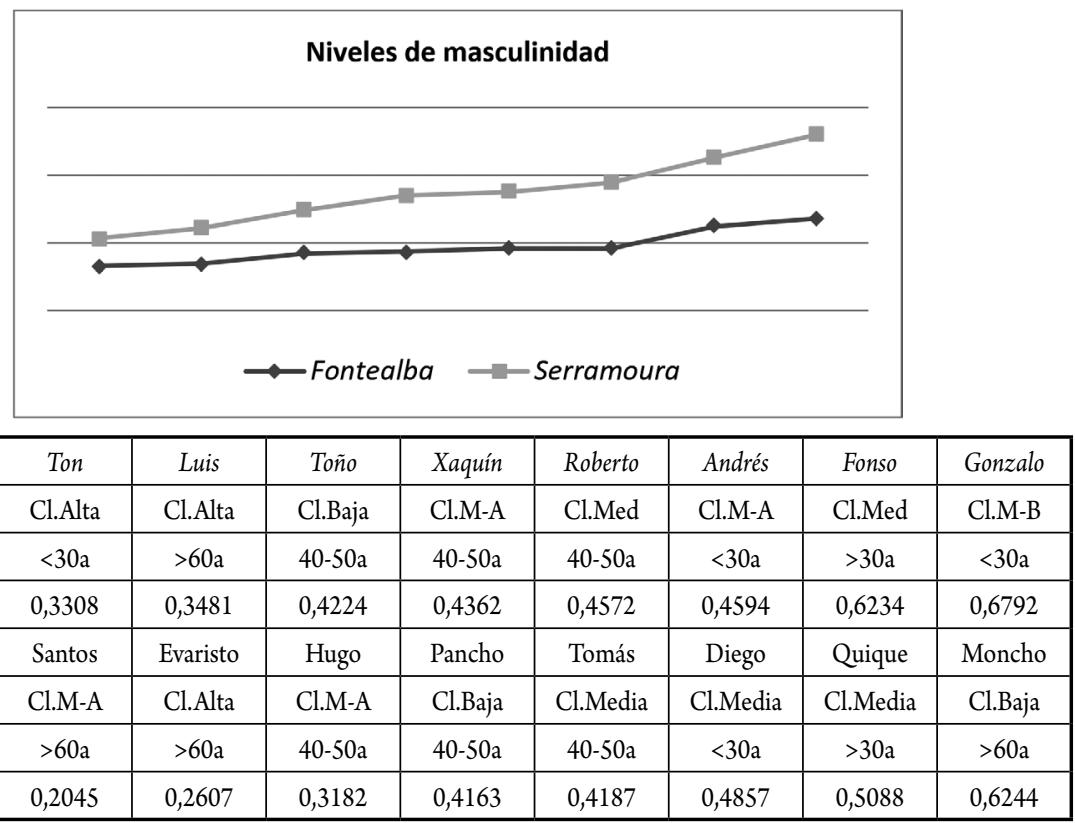

Fuente: elaboración propia. 
En Fontealba, los personajes que obtienen las puntuaciones más bajas según los indicadores de la tabla 1 , esto es, que mantienen los patrones clásicos de la masculinidad hegemónica, son los de Ton (un joven con poder adquisitivo alto preocupado por su aspecto físico y caracterizado por el menosprecio constante a su pareja y comentarios machistas recurrentes) y Luís Douro (patriarca y jefe de la empresa familiar, autoritario en ambos ambientes, y que ejerce un alto grado de control sobre las mujeres de su entorno). Los modelos de masculinidad menos dominante los poseen los personajes que, en parte, dan réplica a los anteriores: Fonso Douro, el hijo del empresario que se distancia del modelo paterno tanto en el ámbito profesional (artista) como en el de las relaciones intergénero, y Gonzalo Vilar, despedido de su trabajo, y que mantiene una relación amorosa bastante igualitaria con la hija rebelde del patriarca, Nina Douro.

En los niveles intermedios, aunque más próximos al modelo de masculinidad hegemónica que al igualitario, hallamos personajes de mediana edad, de diferente formación y categoría laboral, pero que comparten el rasgo de estar sometidos al poder del empresario Douro: desde su mano derecha, Xaquín, su exempleado Roberto o el mecánico y marido de su mayordoma, Toño, a su otro hijo, Andrés Douro, capataz del invernadero.

En cuanto a Serramoura, la serie sigue los patrones ya observados en Fontealba. El modelo de masculinidad hegemónica es el que siguen los personajes de mayor poder, económico o laboral: Santos, mafioso dedicado a la venta de drogas; Evaristo Fiúza, empresario maderero y uno de los máximos caciques del pueblo; y Hugo, su mano derecha. Por el contrario, el personaje que presenta una masculinidad menos tradicional aparece desvinculado del ámbito laboral. Se trata de Moncho, jubilado, padre de la policía coprotagonista de la serie, dedicado al cuidado del hogar.

En los niveles intermedios, se encuentran los personajes sujetos a un ámbito laboral altamente jerárquico como es el de la Guardia Civil (el teniente Tomás Penedo, el coprotagonista Diego Bazán y, en un rango inferior, 
Quique), y correspondiendo esta jerarquía a su nivel de mayor tendencia a la masculinidad hegemónica. Junto a ellos, un personaje de clase obrera, Pancho, que presenta un comportamiento ambivalente desde el punto de vista de la masculinidad en la trama amorosa con su exmujer.

\section{Correlaciones entre clase social e indicadores de masculinidad igualitaria}

El análisis descriptivo y el unidireccional ANOVA entre la variable de clase social y la de indicadores de masculinidad igualitaria muestra una media de masculinidad en el global de los personajes analizados de 0,4231 \pm 0,12909. La variación de estas medias por clases sociales se muestra en la tabla 2.

\section{Tabla 2. Correlación entre clase social e indicadores de masculinidad igualitaria}

\begin{tabular}{|c|c|c|c|c|c|}
\hline $\begin{array}{c}\text { Baja } \\
(\mathrm{n}=3)\end{array}$ & $\begin{array}{c}\text { Media baja } \\
(\mathrm{n}=1)\end{array}$ & $\begin{array}{c}\text { Media } \\
(\mathrm{n}=5)\end{array}$ & $\begin{array}{c}\text { Media alta } \\
(\mathrm{n}=5)\end{array}$ & $\begin{array}{c}\text { Alta } \\
(\mathrm{n}=2)\end{array}$ & Total N=16 \\
\hline $0,44887 \pm .11758$ & 0,6652 & $0,4825 \pm 0,07675$ & $0,3283 \pm 0,08411$ & $0,2919 \pm 0,04412$ & $0,4231 \pm 0,12909$ \\
\hline
\end{tabular}

Fuente: elaboración propia.

Un dato interesante de estas correlaciones y que se analizará en el apartado final es que la representación de la masculinidad igualitaria se da entre los personajes masculinos que pertenecen a la clase social baja (porque están jubilados o desempleados), mientras que aquellos de clase alta tienden a presentar los comportamientos propios y característicos de la masculinidad hegemónica.

En efecto, tal y como se visualiza en la figura 2, los patriarcas y empresarios de ambas series, Luis (Fontealba) y Evaristo (Serramoura) se sitúan en un extremo, el del modelo de masculinidad hegemónica del que nos habla Connell (2005), mientras que son los personajes de clase social baja o media-baja, Moncho (Serramoura) y Gonzalo (Fontealba), los que se comportan de acuerdo con un modelo de masculinidad igualitario. 


\section{Figura 2. Dispersión de todos los personajes en relación con su clase social e indicadores de masculinidad igualitaria.}

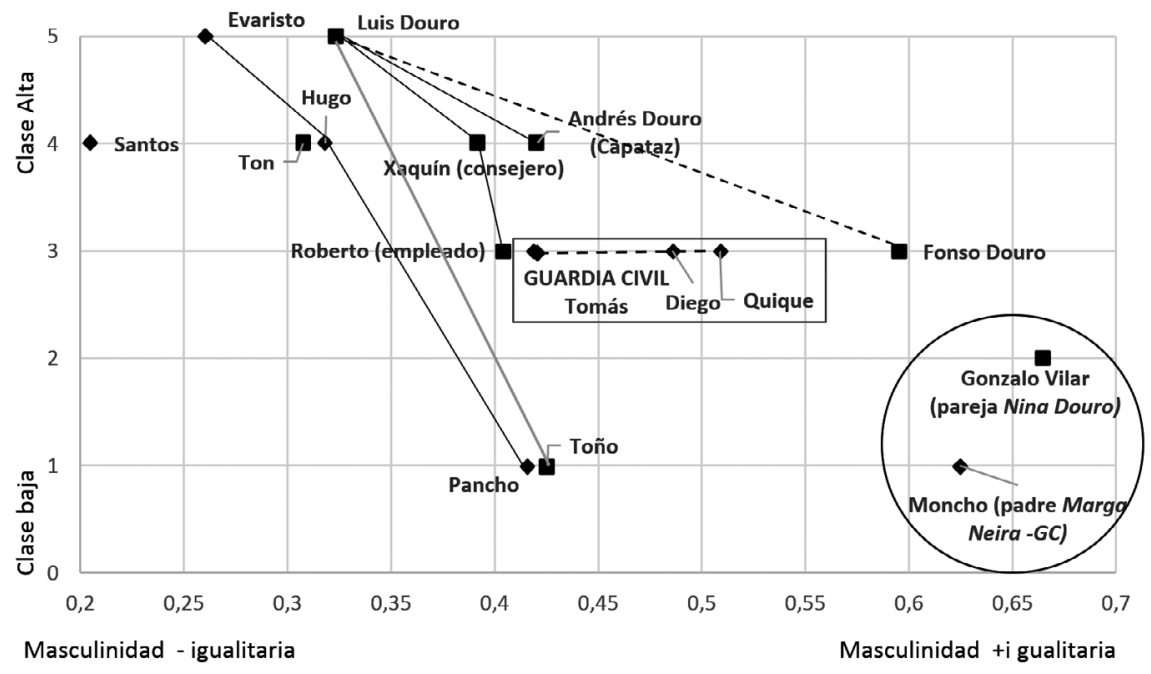

Fuente: elaboración propia.

La figura de dispersión nos muestra también la tendencia a manifestar una masculinidad más igualitaria conforme desciende la clase social y, de acuerdo con las relaciones paradigmáticas establecidas por ambas series, también la jerarquía de poder que posee el personaje. Así, en Fonteal$b a$, bajo las órdenes directas del empresario y con un nivel intermedio de masculinidad hegemónica que recuerda el modelo de masculinidad empresarial de la que habla Connell (2005) se sitúan Xaquín, que ejerce de mano derecha del empresario, y sus empleados directos e indirectos, incluido su hijo Andrés. Se desmarcan de esta influencia, Fonso, el vástago artista que no trabaja en la empresa familiar, y Gonzalo, el yerno de su díscola hija y al que despide. Ambos personajes poseen el rango de masculinidad más igualitaria de la serie.

Del mismo modo, en Serramoura se replica el patrón de menor tendencia a la masculinidad hegemónica conforme desciende la clase social y la posición en la jerarquía de poder del ámbito laboral para cada agrupación de personajes. Así, a las órdenes de Evaristo, Hugo matiza ligeramente su comportamiento, y su empleado Pancho, algo más; mientras que en la comandancia de la Guardia Civil, los personajes muestran un compor- 
tamiento más propio de la masculinidad hegemónica conforme ostentan mayor graduación.

Esta tendencia sostenida para ambas series muestra una aparente excepción. Se trata de Toño (Fontealba) y Pancho (Serramoura), dos personajes de clase social baja que, a diferencia de Gonzalo (Fontealba) y Moncho (Serramoura), se rigen por comportamientos tradicionalmente patriarcales. La interpretación de esta dicotomía puede realizarse desde la observación de las relaciones paradigmáticas entre personajes masculinos y femeninos, de acuerdo con las tramas narrativas de las que participan. Así, los personajes que presentan un comportamiento más igualitario actúan como sostén de mujeres fuertes (Gonzalo es pareja de Nina Douro, la hija díscola del empresario; Moncho es el padre jubilado de la policía coprotagonista). Mientras que los personajes que muestran una masculinidad hegemónica en el ámbito de lo privado no asumen tareas de cuidado, sino que reproducen el desprecio a la mujer en el ámbito laboral como base del conflicto emocional. Toño (Fontealba) reprocha a su esposa la fidelidad a los Douro como mayordoma pese a haber dejado de percibir un sueldo, y Pancho (Serramoura), enamorado aún de su exmujer, representa el dilema entre animarla a ascender profesionalmente en la intimidad y retractarse en público ante iguales.

\section{Correlaciones entre los indicadores de masculinidad igualitaria}

Por último, con el objetivo de hallar patrones de congruencia recurrentes en la configuración de los personajes masculinos, y reevaluar cuáles de las variables utilizadas se adecúan mejor al análisis de masculinidad igualitaria, se han correlacionado las categorías bidimensionales con los indicadores de masculinidad igualitaria. Así, de las 351 posibles correlaciones, 105 han resultado estadísticamente significativas. De estas, 40 son correlaciones fuertes $(r \geq 0,7)$ y 47 muy significativas $(p \leq 0,01)$. Aquí expondremos los 27 casos de correlación más significativa $(r \geq 0,7, p \leq 0,01)$. En la tabla 3 , se destacan aquellas categorías que formarían parte del prototipo de masculinidad más igualitario en las series analizadas. Como puede observarse, corresponde a un personaje masculino que se desempeña de manera muy diferente de la tradicional en el ámbito de lo privado e íntimo. 


\section{Tabla 3. Correlaciones de los indicadores y el nivel de masculinidad igualitaria}

\begin{tabular}{|l|l|}
\hline \multicolumn{1}{|c|}{ Categoría bidimensional } & \multicolumn{1}{c|}{ Valores de correlación } \\
\hline Cuida a los hijos (si los tiene) & $r=0,999, n=4 p=0,001$ \\
\hline Antepone su familia a su trabajo & $r=0,818, n=15 \mathrm{p}=0,00$ \\
\hline Antepone su familia a sus aficiones & $r=0,877, n=13 p=0,00$ \\
\hline Acepta a las mujeres como superiores profesionales & $r=0,750, n=16 p=0,001$ \\
\hline Tiene amistades femeninas & $r=0,797, n=16 p=0,00$ \\
\hline Es capaz de expresar sus sentimientos & $r=0,727, n=16 p=0,001$ \\
\hline No se siente superior a la mujer & $r=0 ., 828, n=16 p=0,00$ \\
\hline No le preocupan temas tradicionalmente masculinos & $r=0,844, n=16 p=0,00$ \\
\hline
\end{tabular}

Fuente: elaboración propia.

En cuanto a la correlación entre las categorías bidimensionales de masculinidad, podemos observar ciertos patrones si las agrupamos según las áreas de interacción de los personajes en la ficción (tabla 4). Esto es, si nos detenemos a interpretar estas categorías, de acuerdo con el close reading de los universos simbólicos presentados por las series, como parte de la expresión de la personalidad en la intimidad o en las relaciones sociales, en el hogar y la vida familiar, o en el ámbito laboral.

\section{Tabla 4. Correlaciones entre las categorías bidimensionales de masculinidad}

\begin{tabular}{|c|c|c|}
\hline \multirow{2}{*}{ Colabora en tareas de limpieza en casa } & Hace la compra & $\mathrm{r}=0,828, \mathrm{n}=16 \mathrm{p}=0,00$ \\
\hline & Cocina & $\mathrm{r}=0,938, \mathrm{n}=16 \mathrm{p}=0,00$ \\
\hline Hace la compra & Cocina & $\mathrm{r}=0,806, \mathrm{n}=16 \mathrm{p}=0,00$ \\
\hline Cocina & $\begin{array}{l}\text { Ejerce labores domésticas igual o más que su } \\
\text { pareja }\end{array}$ & $\mathrm{r}=0,948, \mathrm{n}=7 \mathrm{p}=0,001$ \\
\hline No se siente superior a la mujer & $\begin{array}{l}\text { Ejerce labores domésticas igual o más que su } \\
\text { pareja }\end{array}$ & $\mathrm{r}=0,884, \mathrm{n}=7 \mathrm{p}=0,008$ \\
\hline \multirow{5}{*}{ Antepone su familia a sus aficiones } & Es capaz de expresar sus sentimientos & $\mathrm{r}=0,807, \mathrm{n}=13 \mathrm{p}=0,001$ \\
\hline & No ejerce violencia en el ámbito profesional & $\mathrm{r}=0,702, \mathrm{n}=13 \mathrm{p}=0,007$ \\
\hline & Tiene amistades femeninas & $\mathrm{r}=0,815, \mathrm{n}=13 \mathrm{p}=0,001$ \\
\hline & Permite la toma de decisiones a la mujer & $\mathrm{r}=0,793, \mathrm{n}=13 \mathrm{p}=0,001$ \\
\hline & $\begin{array}{l}\text { No le preocupan temas tradicionalmente } \\
\text { masculinos }\end{array}$ & $\mathrm{r}=0,742, \mathrm{n}=13 \mathrm{p}=0,004$ \\
\hline Antepone su familia a su trabajo & Antepone su familia a sus aficiones & $\mathrm{r}=0,933, \mathrm{n}=13 \mathrm{p}=0,00$ \\
\hline
\end{tabular}




\begin{tabular}{|c|c|c|}
\hline \multirow{2}{*}{$\begin{array}{c}\text { Alienta a una mujer en el ascenso } \\
\text { profesional }\end{array}$} & $\begin{array}{c}\text { Acepta a las mujeres como superiores } \\
\text { profesionales }\end{array}$ & $\mathrm{r}=0,786, \mathrm{n}=16 \mathrm{p}=0,00$ \\
\cline { 2 - 3 } & Permite la toma de decisiones a la mujer & $\mathrm{r}=0,782, \mathrm{n}=16 \mathrm{p}=0,00$ \\
\hline $\begin{array}{c}\text { Acepta a las mujeres como superiores } \\
\text { profesionales }\end{array}$ & No cambia de actitud ante hombres o mujeres & $\mathrm{r}=0,716, \mathrm{n}=16 \mathrm{p}=0,002$ \\
\hline \multirow{2}{*}{$\begin{array}{c}\text { No le preocupan temas } \\
\text { tradicionalmente masculinos }\end{array}$} & Tiene amistades femeninas & $\mathrm{r}=0,815, \mathrm{n}=16 \mathrm{p}=0,00$ \\
\cline { 2 - 3 } & Permite la toma de decisiones a la mujer & $\mathrm{r}=0,741, \mathrm{n}=16 \mathrm{p}=0,001$ \\
\cline { 2 - 3 } & No se siente superior a la mujer & $\mathrm{r}=0,799, \mathrm{n}=16 \mathrm{p}=0,00$ \\
\cline { 2 - 3 } & No aficiones de ocio masculinas & $\mathrm{r}=0,761, \mathrm{n}=16 \mathrm{p}=0,001$ \\
\hline \multirow{2}{*}{$\begin{array}{c}\text { No toma la iniciativa en las relaciones } \\
\text { sexuales }\end{array}$} & No aficiones de ocio masculinas & $\mathrm{r}=0,713, \mathrm{n}=16 \mathrm{p}=0,002$ \\
\hline
\end{tabular}

Fuente: elaboración propia.

De la tabla 4 se desprenden los que pasaríamos a denominar factores característicos de la masculinidad igualitaria: a) corresponsabilidad en las tareas del hogar, b) capacidad para poner sus propias aficiones en segundo término, c) aceptación de la vertiente profesional de la mujer y d) desinterés por los temas tradicionalmente masculinos.

\section{Discusión y conclusiones}

Una primera conclusión derivada de este estudio tiene que ver, precisamente, con lo que no aparece. Nos estamos refiriendo a la ausencia del modelo de masculinidad subordinada según el planteamiento de Connell (2005). Ambas series apuestan, de manera deliberada o no, por un planteamiento heteronormativo en el que no tienen cabida personajes masculinos homosexuales. Del mismo modo, no se representa aproximación alguna al modelo new lad propuesto por Gill (2014). Se confirma, una vez más, en el ámbito de lo dramático costumbrista de la ficción española, la heterosexualidad masculina como marca (Núñez y Pérez, 2013).

Centrándonos ya en lo que se muestra, un resultado por tener presente es el predominio en ambas series del modelo hegemónico de masculinidad a la hora de construir personajes masculinos. El espacio público que representa la esfera laboral sigue rigiéndose por los mismos patrones de masculinidad hegemónica de la que nos habla Connell (2005). Se trata de un hombre "duro" (Badinter, 1993) que deja claro el ejercicio de su poder, no solo frente a sus trabajadores, sino en el escenario privado de las 
relaciones afectivas con las mujeres de su entorno. Y este patrón se refuerza con la masculinidad de tipo empresarial que Connell \& Wood (2005) detectan en entornos laborales jerárquicos y altamente competitivos, y que los escasos estudios de las series dramáticas de ficción españolas tienden a corroborar. Así, López, Cobo y Hermida (2013, pp. 100-101) dividen los personajes masculinos en el drama televisivo entre bondadosos y tiranos, reconociendo a los primeros como sensibles y afectuosos, pero, sobre todo, y a efectos de nuestros hallazgos, "distantes con respecto a las tramas ambiciosas de poder".

Resulta prometedor, sin embargo, la aparición de personajes masculinos que rompen esta tendencia y presentan una masculinidad que hemos denominado igualitaria. Son hombres que se feminizan en el espacio privado, se corresponsabilizan en las tareas del hogar y entienden y valoran el desempeño profesional de sus parejas. Sin embargo, una mirada más atenta a estos personajes nos confronta con una paradoja interesante: en ambos casos, son personajes que no trabajan (ya porque se han jubilado, ya porque han sido despedidos), es decir, que — de alguna manera- han sido desterrados de lo público, auténtico escenario en el que se sigue ejerciendo y visibilizando el poder. Y aquí surge la pregunta: ¿seguirían manteniendo una masculinidad igualitaria si también trabajaran fuera de casa, es decir, si la identidad profesional siguiera vigente?

En último extremo, y al hilo de esta paradoja, al ser personajes que no tienen hijos pequeños, tampoco podemos ver cómo sería su desempeño en el cuidado emocional de la crianza, tarea que, como bien ha denunciado Hays (1998), forma parte de un modelo de maternidad intensiva que resulta agotadora para las mujeres trabajadoras. Sin embargo, en ambas series, ellas son personajes fuertes, profesionalmente activos, que se alejan de las tramas adscritas a la esfera reproductiva, lo cual nos acerca a la reflexión de Galán (2007) sobre el movimiento inverso al que debería tender el hombre que cada vez más se representa en los personajes femeninos de la ficción española. Parece ser que las nuevas masculinidades emergen de manera natural en la esfera reproductiva, como feminización o alteración de la masculinidad que sigue presentándose como hegemónica (la arraigada 
a la ambición y el ejercicio de poder en el ámbito público); por ejemplo, la dificultad en representar al cuidador masculino sin recurrir al humor o las marcas de transgresión que analizan Araüna, Tortajada \& Willem (2018). Estos personajes masculinos más igualitarios, permiten a su vez la mayor integración del personaje femenino que los complementa a la esfera laboral, pero en este desplazamiento mutuo lo que se aleja definitivamente es la posibilidad de visualizar como alternativa posible en la ficción contemporánea un modelo de corresponsabilidad en ambas esferas. Por ello, las series de ficción analizadas no resultan propositivas en un sentido transgresor, ya que no presentan alternativas realmente rupturistas con el modelo de masculinidad hegemónica.

\section{Referencias}

Araüna, N., Tortajada, I. \&Willem, C. M. (2018). Portrayals of Caring Masculinities in Fiction Film: The Male Caregiver in Still Mine, Intouchables and Nebraska. Masculinities \& Social Change, 7(1), 82-102. DOI: https://doi.org/10.17583/MCS.2018.2749

Asbeek Brusse, E. D., Fransen, M. L., Smit, E. G. (2016). Framing in Entertainment-Education: Effects on Processes of Narrative Persuasion. Health Communication Journal, 32(12), pp. 1501-1509. DOI: https://doi.org/10.1080/10410236.2016.1234536

Badinter, E. (1993). XY. : la identidad masculina. Madrid, España: Alianza Editorial.

Barlovento Comunicación. (2017, marzo 31). Análisis de audiencias TV marzo 2017. Recuperado de https://www.barloventocomunicacion.es/audiencias-mensuales/analisis-marzo-2017/

Belmonte Arocha, J., \& Guillamón Carrasco, S. (2008). Co-educar la mirada contra los estereotipos de género en TV. Comunicar, 21, 115-120. DOI: https://doi.org/10.3916/c31-2008-01-014

Bourdieu, P. (1998).La dominación masculina. Barcelona, España: Anagrama. 
Braddock, K. \& Dillard, J. P. (2016). Meta-analytic evidence for the persuasive effect of narratives on beliefs, attitudes, intentions, and behaviors. Communication Monographs, 83(4), 446-467. DOI: https:// doi.org/10.1080/03637751.2015.1128555

Bromley, R. (2000). The theme that dare not speak its name: Class and recent british film. En S. R. Munt (Ed.), Cultural studies and the working class: Subject to chance (pp. 51-68). Londres, UK: Cassell.

Bruner, J. (2004). Realidad mental y mundos posibles. Barcelona, España: Gedisa.

Brusse, E. D. A., Fransen, M. L. \& Smit, E. G. (2017). Framing in entertainment-education: Effects on processes of narrative persuasion. Health Communication, 32(12), 1501-1509. DOI: https://doi.or $\mathrm{g} / 10.1080 / 10410236.2016 .1234536$

Buckingham, D. (1987) Public Secrets: EastEnders and its audiences. Londres, RU: British Film Institute.

Buonanno, M. (1999). El drama televisivo: identidad y contenidos sociales. Barcelona, España: Gedisa.

Buonanno, M. (2004). Realtà multiple: concetti, generi e audience della fiction $T V$. Nápoles, Italia: Liguore.

Buonanno, M. (2012) La fiction italiana: narrazioni televisive e identitànazionale. Roma, Italia: Laterza.

Butler, J. (2004). Undoing gender. Nueva York, EE. UU.: Routledge.

Casetti, F. y Di Chio, F. (1999). Análisis de la televisión: instrumentos, métodos y prácticas de investigación. Barcelona, España: Paidós.

Castelló Cogollos, E. (2004). Mecanismos de construcción de la identidad cultural en las series de ficción: el caso de la televisión auto- 
nómica en España. Estudios sobre las Culturas Contemporáneas, 10 (20), 45-77. Recuperado de http://www.redalyc.org/articulo.oa?id=31602003

Castelló Cogollos, E. (2007). The production of television fiction and nation building: The catalan case. European Journal of Communication, 22(1), 49-68.DOI: https://doi.org/10.1177/0267323107073747

Castelló Cogollos, E. (2010). Dramatizing proximity: Cultural and social discourses in soap operas from production to reception. European Journal of Cultural Studies, 13(2), 207-223. DOI: https:// doi.org/10.1177/1367549409352274

Castelló Cogollos, E. (2016a). Anderson and the media: The strength of 'imagined communities'. Debats: Revista de cultura, poder i societat, 130(1), 75-80. doi: http://dx.doi.org/10.28939/iam.debatsen.2016-5

Castelló Cogollos, E. (2016b). Televisión pública e imaginarios culturales en conflicto: de la transición a la posdemocracia. En J. Rius-Ulldemolins y J. A. Rubio (Eds.), Treinta años de políticas culturales en España: participación cultural, gobernanza territorial e industrias culturales (pp. 375-391). Valencia, España: Universidad de Valencia.

Chicharro Merayo, M. (2009). Recreando la sociedad del pasado: modernización y conflicto social en La Señora. Anàlisi: quaderns de comunicació i cultura, 39, 51-70. Recuperado de https://ddd.uab.cat/ pub/analisi/02112175n39/02112175n39p51.pdf

Chicharro Marayo, M. (2012). Telenovelas and society: Constructing and reinforcing the nation through television fiction. European Journal of Cultural Studies, 16(2), 211-225. DOI: https://doi. org/10.1177/1367549412467178

Connell, R. W. (2005). Masculinities. Cambridge, RU: Polity Press. 
Connell, R. W. \& Messerschmidt, J. W. (2005). Hegemonic masculinity: Rethinking the concept. Gender \& society, 19(6), 829-859. DOI: https://doi.org/10.1177/0891243205278639

Connell, R. W. \& Wood, J. (2005). Globalization and business masculinities. Men and Masculinities, 7(4), 347-364. DOI: https://doi. org/10.1177/1097184X03260969

Couldry, N. (2008). Media discourse and the naturalisation of categories. En R. Wodak \& V. Koller (Eds.), Handbook of communication in the public sphere (pp.67-87). Berlín, Alemania: Walter de Gruyter.

Couldry, N. (2011). Class and contemporary forms of 'reality' production, or hidden injuries of class. En H. Wood y B. Skeggs (Eds.), Reality television and class (pp. 33-44). Basingstoke, RU: Palgrave Macmillan.

Crenshaw, K. (1991) Mapping the margins: Intersectionality, identity politics, and violence against women of color. Stanford Law Review, 43(6), 1241-1299. DOI: https://doi.org/10.2307/1229039

Dhoest, A. \& Simon, N. (2016). Still 'watching' TV? The consumption of TV fiction by engaged audiences. Media and Communication, 4(3), 176-184. DOI: http://dx.doi.org/10.17645/mac.v4i3.427

Dyer, R., Geraghty, C., Jordan, M., Lovell, T., Patterson, R. \& Stewart, J. (1981) Coronation street. Londres, RU: British Film Institute.

Galán Fajardo, E. (2007). Construcción de género y ficción televisiva en España. Comunicar, 28, 229-236. Recuperado de https://recyt.fecyt.es/index.php/comunicar/article/view/25998

García de Castro, M. (2008). Los movimientos de renovación en las series televisivas españolas. Comunicar, 20(15), 147-153. DOI: https:// doi.org/10.3916/c30-2008-02-008 
Gaunlett, D. (2008). Media, gender and identity: An introduction. Londres, RU: Routledge.

Gill, R. (2014). Powerful women, vulnerable men and postfeminist masculinity in men's popular fiction. Gender and Language, 8(2), 185204. DOI: https://doi.org/10.1558/genl.v8i2.185

González, M. J. y Jurado Guerrero, T. (2015). Padres y madres corresponsables: una utopía real. Madrid, España: Catarata.

Guarinos, V. (Ed.) (2013). Hombres en serie: construcción de la masculinidad en los personajes de ficción seriada española de televisión. Madrid, España: Fragua.

Guarinos, V. (2015). El país de los hombres perdidos: personajes masculinos en el abismo en el cine español de la Transición. Área Abierta, 15(1), 3-14. DOI: https://doi.org/10.5209/rev_ARAB.2015. v15.n1.47615

Hays, S. (1998). Las contradicciones culturales de la maternidad. Barcelona, España: Paidós.

Igartua Perosanz, J. J. (2007). Persuasión narrativa: el papel de la identificación con los personajes a través de las culturas. Alicante, España: Club Universitario.

Jakobsson, P. \& Stiernstedt, F. (2018). Naturalizing social class as a moral category on swedish mainstream television. Nordicom Review, 39(1), 81-94. DOI: https://doi.org/10.2478/nor-2018-0003

Jordan, M. (1981). Realism and convention. En R. Dyer, C. Geraghty, M. Jordan, T. Lovell, R. Patterson \& Stewart, J., Coronation street. (pp. 27-39). Londres, RU: British Film Institute.

Kimmel, M. (2008). Guyland: The perilous world where boys become men. Nueva York, EE. UU.: Harper Collins Publishers. 
Lacalle Zalduendo, M.R.y Gómez Morales, B. M. (2016).La representación de las mujeres trabajadoras en la ficción televisiva española. Comunicar, 47, 59-67. DOI: https://doi.org/10.3916/C47-2016-06

Lacalle Zalduendo, M. R. y Gómez Morales, B. M. (2017). La recepción televisiva española en la era multipantalla. Comunicación y Sociedad, 30, 197-216. Recuperado de http://www.comunicacionysociedad. cucsh.udg.mx/index.php/comsoc/article/view/6135

Linkon, S. L. (2014). Men without Work: White working-class masculinity in deindustrialization fiction. Contemporary Literature, 55(1), 148-167. DOI: https://doi.org/10.1353/cli.2014.0003

Livingstone, S. (1990). Making sense of television: The psychology of audience's interpretation. Oxford, RU: Pergamon Press.

López Rodríguez, F. J., Cobo Durán, S. y Hermida, A. (2013). Diferencias de perfiles de masculinidad televisiva de ficción en la comedia y en el drama. En V. Guarinos (Coord.), Hombres en serie: construcción de la masculinidad en los personajes de ficción seriada española de televisión (pp. 88-102). Madrid, España: Fragua.

Mantsios, G. (2003). Media magic: Making class invisible. En P. S. Rothenberg (Ed.), Race, class, and gender in the United States: An integrated study (pp. 93-101). Nueva York, EE. UU.: MacMillan.

Menéndez Menéndez, I. (2008). Discursos de ficción y construcción de la identidad de género en televisión. Palma de Mallorca, España: Universidad de las Islas Baleares.

Núñez Domínguez, T. y Pérez Gómez, M. Á. (2013). La heterosexualidad masculina como marca en las series de ficción televisiva. En V. Guarinos (Coord.), Hombres en serie: construcción de la masculinidad en los personajes de ficción seriada española de televisión (pp. 56-61). Madrid, España: Fragua. 
O’Donnell, H. (1999). Good times, bad times: Soap operas and society in Western Europe. Londres, RU: Leicester University Press.

Oliva, M. (2013). Telerrealidad, disciplina e identidad: los makeover shows en España. Barcelona, España: UOC.

Porto, M. P. (2005). Political controversies in Brazilian TV fiction: Viewers' interpretations of the telenovela Terra Nostra. Television \& New Media, 6(4), 342-359. DOI: https://doi. org/10.1177/1527476405279862

Rueda Laffond, J. C. (2009). ¿Reescribiendo la historia? Una panorámica de la ficción histórica televisiva española reciente. Alpha (Osorno), 29, 85-104. doi: https://doi.org/10.4067/S071822012009002900007

Segarra, M. y Carabí, A. (Eds.) (2000). Nuevas masculinidades. Barcelona, España: Icaria.

Song, G. \& Lee, T.K. (2012). "New Man" and "New Lad" with chinese characteristics? Cosmopolitanism, cultural hybridity and men's lifestyle magazines in China. Asian Studies Review, 36(3), 345-367. DOI: https://doi.org/10.1080/10357823.2012.711808

Stiernstedt, D. \& Jakobsson, P. (2017). Watching reality from a distance: Class, genre and reality television. Media, Culture \& Society, 39(5), 697-714. DOI: https://doi.org/10.1177/0163443716663643

Tufte, T. (2000). Living with the Rubbish Queen: Telenovelas, culture and modernity in Brazil. Luton, RU: University of Luton Press.

Vasallo de Lopes, M. I., Simoes Borelli, S. H. \& Da Rocha Resende, V. (2002). Vivendo com a telenovela: mediaçoes, recepçao, teleficcionalidade. São Paulo: Summus Editorial 